\title{
Corrosion and the role of structural aluminum alloys in the construction of oil and gas wells
}

\author{
Mikhail Gelfgat ${ }^{1, *}$, Alexey Alkhimenko ${ }^{2}$, and Sergey Kolesov ${ }^{3}$ \\ ${ }^{1}$ Gubkin Russian State Oil and Gas University, Oil \& Gas Wells Drilling Department, 65, Leninsky Prospekt 119991 Moscow, Russia \\ ${ }^{2}$ St.Petersburg Polytechnical University, R\&D center Weatherford-Polytechnic, Russia \\ ${ }^{3}$ Weatherford, USA
}

\begin{abstract}
This paper presents the main research results and examples of structural aluminium alloys (SAA) effective use in the oil and gas wells construction onshore and offshore. The known application cases are drill pipes, tubing and casing. Competitive properties of SAA for hydrocarbons exploration and production were identified as strength-to-weight ratio, high total corrosion resistance, including dissolved hydrogen sulphide and carbon dioxide, absence of cold-shortness effect. The issues with the natural properties of aluminum alloys requiring process and structural corrections were addressed as well. Technical solutions to neutralize characteristics, which limited SAA use in the wells construction have been advised and examples of implementation shown. Among them, technology of surface layers modification, coatings and methods of isolation contacts with other material, system of integrated corrosion protection and optimization of operation environment. Aluminum drilling riser (ADR) is one of the most striking examples of the object from SAA. ADR presents integrated solution of SAA application problems. Finally, SAA could successfully address well construction corrosion issues.
\end{abstract}

\section{Introduction}

Despite some obvious and proven SAA advantages in comparison with conventional tube semis, application of aluminum tubular products remains rather limited. This circumstance can be explained by certain conservatism of the engineering community that still relies on generally accepted opinion on aluminum alloy drawbacks. These include low hardness contributing to increased wear of the surface in contact with rock or other material and limited corrosion resistance in some conditions - increased chloride content as example.

Many experts believe that these negative properties prevail over such advantages as hydrogen sulfide corrosion resistance, stability of properties at low temperatures and a huge advantage in strength-toweight ratio of the tubular structure - a freely suspended SAS string is almost twice as long as the string made of steel. Such approach, subject to a wide offering of advanced high-strength steel tubes and special alloy tubes resistant to hydrogen sulfide corrosion, helps to solve current problems in a traditional conservative way [1].

Nevertheless, there are certain commercial products on the market using SAA and showing very positive results: Light-alloy improved dependability drill pipes (LAIDP) [2 - 6]; Aluminium alloy casing (LACT) and tubing (LAT) [6 - 7]; Aluminum drilling riser of ADRDW type [8 - 10]. Some SAA made prototypes, or full scale samples have been developed, but never tested in the filed: production and intervention risers, interfile pipeline $[11-12]$.

Increasingly difficult conditions of field development result in substantially higher costs of well drilling, completion and operation, which were aggravated by the industry transition towards lower oil prices. This is why the authors again offering to consider alternative "aluminum" solutions of the problems in well construction.

\section{SAA competitive properties}

\subsection{Strength-to-weight ratio}

Successful development of SAA-based drilling tools and risers was due to undeniable advantages, first, high strength-to-weight ratio significantly exceeding that of high-strength steels. While designing the tubular structures of the same type it is reasonable to compare materials by strength-to-weight ratios at the stage of material selection (Table 1).

Table 1: Structural material strength-to-weight ratios

\begin{tabular}{|l|c|c|}
\hline \multirow{2}{*}{ Materials } & $\begin{array}{c}\text { Specific ultimate } \\
\text { strength }\end{array}$ & $\begin{array}{c}\text { Specific yield } \\
\text { point }\end{array}$ \\
\cline { 2 - 3 } & $\sigma_{\mathrm{v}} / \gamma, \mathrm{km}$ & $\sigma_{0,2} / \gamma, \mathrm{km}$ \\
\hline Titanium alloys & $8.8-28$ & $7.7-26$ \\
\hline Steel & $6.4-15$ & $4.5-14$ \\
\hline Aluminium alloys & $11.1-26$ & $6.0-24$ \\
\hline
\end{tabular}


Aluminum alloys have almost twofold strength-toweight ratios as compared to steel, and the same as titanium alloys at incomparable smaller cost. Replacement of steel with aluminum in view of the structure weight provides obvious advantages during transportation and handling as similar purpose tubulars usually have $2-2.5$ times smaller unit weight. This can become decisive upon assessment of environmental losses during transportation on weak surface soils in the Arctic. Energy and economic benefits of reduced weight of tubular structure or pipe are also obvious especially in terms of floating craft loading.

\subsection{Absence of cold-shortness effects at low temperatures [1]}

The enhanced operational reliability of aluminum structures in the Arctic conditions is proved by the absence of cold-shortness effect. The static strength, impact strength and ductility only increase with temperatures falling to cryogenic values without any fluctuations. In certain conditions, hydrogen absorbed by steels causes significant irreparable damages to their structure, mostly resulting in increased tendency to brittle failure and cold-shortness at low temperatures.

\subsection{No hydrogen embrittlement}

The increase in the content of hydrogen sulfide is observed in many of oil deposits and, accordingly, the problem of corrosion cracking of steel materials is becoming increasingly important. Search and development of new corrosion-resistant steel grades are associated with high financial costs and are not always effective. SAA semis feature high corrosion resistance in dissolved hydrogen sulfide and carbon dioxide - there is virtually no effect of hydrogen embrittlement of the SAA, which is mainly determined by low natural solubility of hydrogen in aluminum (Fig. 1).
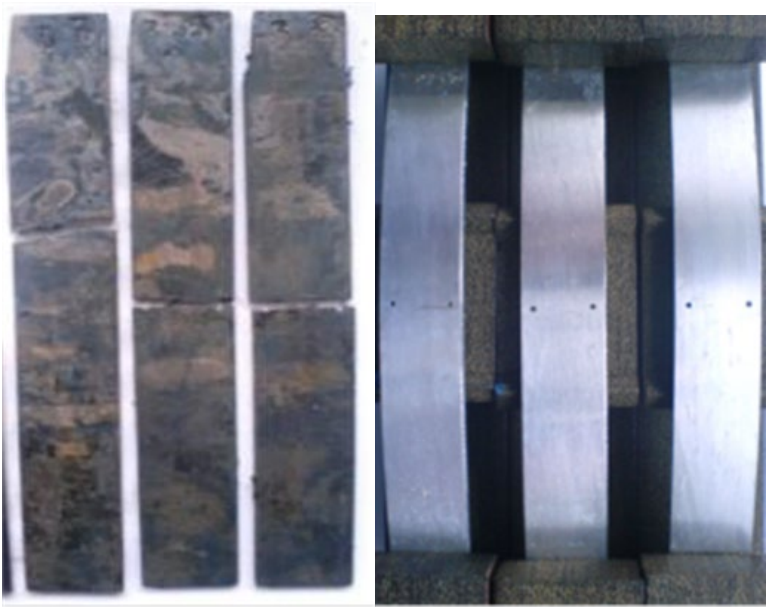

Fig. 1 Photos of samples after corrosion cracking tests in hydrogen sulfide environment as per NACE TM 0177: steel 40KhN2MA after 13 days (left); b) aluminum alloy 1953T1 after 30 days (standard requirement) [1]

\subsection{High total corrosion resistance}

SAA corrosion resistance is defined by the aluminum property to easily passivate, means immediately form a stable and strong oxide film on the aluminum surface and welded connections. High SAA corrosion resistance can be proved, for example, by the results of aluminum and steel tubing application (Fig. 2). Aluminum alloys feature high corrosion resistance in $\mathrm{pH}$ range from 4 to 10 (operational allowance up to 11). In accordance with standard total corrosion tests (as per NACE), the main part of aluminum alloys is classified as highly corrosion-resistant. However, when designing the structures with the use of SAA, the application conditions in terms of corrosion hazard should be always considered. The corrosion resistance of particular SAA semis may be increased using right selection of thermomechanical or heat treatment.
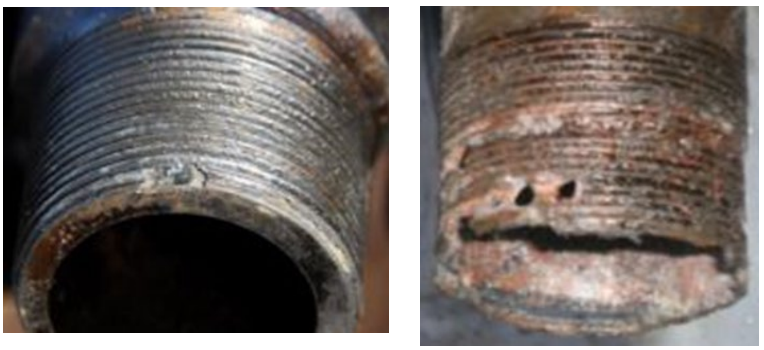

Fig.2 Photos of $73 \mathrm{~mm}(27 / 8$ ") tubing threads used in Samotlor field; pH 7.0; $\mathrm{CO}_{2} 202 \mathrm{mg} / 1 ; \mathrm{H}_{2} \mathrm{~S} 0.75 \mathrm{mg} / \mathrm{l}$ : a) Aluminum tubing after 1.4-year operation (left); b) Steel tubing after 4-months operation.

\subsection{Good processability}

SAA have good ductile and mechanical processability: pressing, stamping, forging, bending, and machining are applicable almost for all alloys. The term "weldability" means a wide set of joint properties, including strength properties and corrosion resistance of the base metal, weld material of the joint and heat-affected zone. The heat input effect in the weld can change the entire set of alloy properties: physical, chemical, structural and strength. By weldability, materials are classified as good, satisfactory and poorly welded. Some aluminum alloys have good or satisfactory weldability, as described below in this paper when discussing ADR development.

\section{SAA properties requiring technological and design solutions}

At the initial design stages, when selecting the material, the designers should pay attention to such natural properties of aluminum alloys that are contrary to the experience of steel semis application in similar equipment manufacturing, e.g.:

- Reduced hardness;

- Increased "bonding" - higher possibility of juvenile bridges of metallic bonds forming upon contacts;

- High negative electrochemical potential. 


\subsection{Reduced hardness and increased "bonding"}

These negative properties of SAA manifest primarily in contact force interactions of the parts and, mainly, with steel elements of the structure such as threaded connections, sliding or transition surfaces. However, if contact conditions are modified by surface treatment or inclusion of an intermediate element, i.e. coating, the consequences of contact would be positively changed.

E.g., aluminum alloys have large natural ductility margin and, therefore, surface plastic shaping can effectively harden them. Thus, Table 2 shows the results of two types of surface plastic strengthening treatment: (1) Impact shot peening; (2) Abrasion-free ultrasonic finish treatment (AfUFT).

Table 2 Results of surface shaping of aluminum alloys

\begin{tabular}{|c|c|c|c|c|c|c|c|c|}
\hline \multirow{3}{*}{$\begin{array}{l}\text { Treatment } \\
\text { method }\end{array}$} & \multicolumn{3}{|c|}{$\begin{array}{c}\text { Residual stresses, } \\
\mathrm{MPa}\end{array}$} & \multicolumn{5}{|c|}{ Microhardness, HV } \\
\hline & \multicolumn{8}{|c|}{ Depth, $\mu \mathrm{m}$} \\
\hline & 0 & 60 & 150 & $\begin{array}{l}3 \\
0\end{array}$ & $\begin{array}{l}1 \\
5 \\
0\end{array}$ & $\begin{array}{l}2 \\
0 \\
0\end{array}$ & $\begin{array}{l}3 \\
0 \\
0\end{array}$ & $\begin{array}{l}5 \\
0 \\
0\end{array}$ \\
\hline $\begin{array}{l}\text { Witness - } \\
\text { "without } \\
\text { treatment" }\end{array}$ & \multicolumn{3}{|c|}{+370} & \multicolumn{5}{|c|}{195} \\
\hline $\begin{array}{l}\text { Bead } \\
\text { blasting one } \\
\text { run by steel } \\
\text { and glass } \\
\text { beads }\end{array}$ & -150 & -330 & +20 & $\begin{array}{l}2 \\
4 \\
1\end{array}$ & $\begin{array}{l}2 \\
1 \\
9\end{array}$ & $\begin{array}{l}2 \\
1 \\
3\end{array}$ & $\begin{array}{l}1 \\
9 \\
3\end{array}$ & $\begin{array}{l}1 \\
9 \\
2\end{array}$ \\
\hline $\begin{array}{l}\text { Bead } \\
\text { blasting - } \\
\text { two runs by } \\
\text { steel beads } \\
\text { and one run } \\
\text { by glass } \\
\text { beads }\end{array}$ & -130 & -320 & +30 & $\begin{array}{l}2 \\
4 \\
7\end{array}$ & $\begin{array}{l}2 \\
2 \\
1\end{array}$ & $\begin{array}{l}2 \\
1 \\
1\end{array}$ & $\begin{array}{l}1 \\
9 \\
5\end{array}$ & $\begin{array}{l}1 \\
9 \\
5\end{array}$ \\
\hline AfUFT & -227 & -460 & -348 & $\begin{array}{l}2 \\
6 \\
8\end{array}$ & $\begin{array}{l}2 \\
4 \\
3\end{array}$ & $\begin{array}{l}2 \\
4 \\
2\end{array}$ & $\begin{array}{l}2 \\
2 \\
5\end{array}$ & $\begin{array}{l}2 \\
0 \\
0\end{array}$ \\
\hline
\end{tabular}

Impact shot peening provided for the following process variables: particle type (metal or ceramic), particle size, process steps.

AfUFT is another surface hardening method, which uses a hard-alloy striker as the main tool, vibrating at the ultrasonic frequency (about $25,000 \mathrm{~Hz}$ ) and providing impact surface shaping. Structurally, AfUFT uses an ultrasonic head with a magnetostrictive converter and a striker installed at the place of the cutter support in the turning machine (Fig. 2).

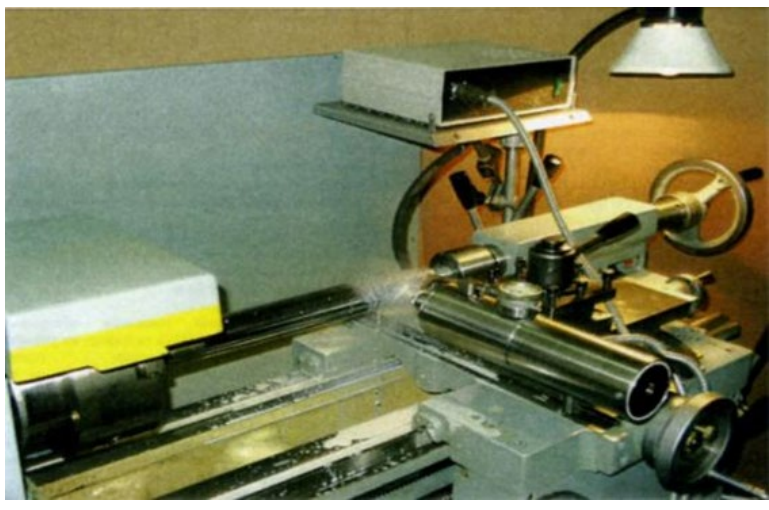

Fig. 2 AfUFT device on the turning machine [1]

The SAA effectively accepts plastic surface hardening mechanical properties are changed at the depth of $500 \mu \mathrm{m}$ and more. In this case, stresses in the surface layers of the cylinder change over from "tension to compression" and hardness values increase by $30 \%$ and more. Such results on modifying the surface of an aluminum alloy part indicate the possibility of improving SAA performance and their acquisition of competitive structural properties.

\subsection{Wear resistance of SAA tubes and threaded connections}

It is known that threaded connections made in aluminum alloy tube have low efficiency that can be a limiting factor for material selection. Such characteristics as the number of "make-ups and break-outs", thread tightness and connection crushing strength are relatively low mainly due to reduced surface hardness and increased tendency of contact surfaces "bonding".

Also, the known problem in application of aluminum drill pipes with steel tool joints includes increased sliding friction losses and physical wear of the pipe body in contact with casing or rock. This is direct consequence of the reduced surface hardness $(120-200$ $\mathrm{HV}$ ) of aluminum tubes. Upon contact force interaction, surface volumes of aluminum materials form juvenile surfaces with metallic bonds with the contacting bodies, resulting in tear (galling), abrasive deterioration and wear. So, it is logical to propose that surface hardness of aluminum tubes should be increased at the points of the highest contact force interaction.

The research aimed of improving LAT threads was arranged. The objective of the study was increasing the surface hardness and decreasing the friction factor on the contact surfaces. The first phase of experiments (see Fig. 3) provided for modifications of cylindrical surfaces of alloy 1953 (alloying system Al-Zn-Mg-Cu). The detonation metallized coating method was applied along with described earlier AfUFT. 


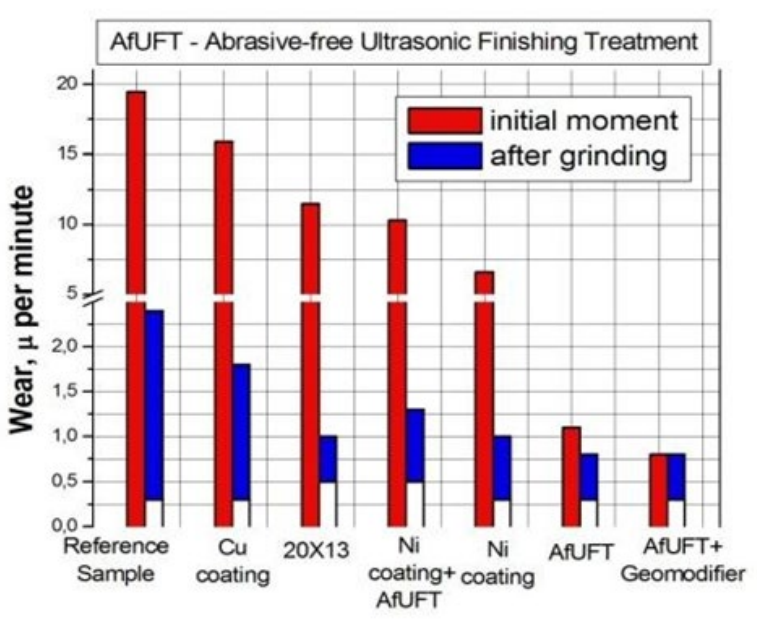

Fig. 3 Wear test of aluminum alloy 1953 with various coatings [1]

The most statistically significant results obtained after the surface running-in period. AfUFT demonstrated the highest effectiveness in decreasing energy and force indicators of the friction process, while simple surface metallization, especially $\mathrm{Cu}$ coating - the lowest. Combined technology of nickel coating with further ultrasonic treatment ( $\mathrm{Ni}$ coating+AfUFT) showed the highest results in decreasing friction factor and torque - by 20 and more times [1].

The second phase of research was development of experimental technologies to make threaded connections for LAT. Threads were treated by application of metal coating compound using the similar wear-resistant coating application and plastic surface hardening by AfUFT (Fig. 4, 5).

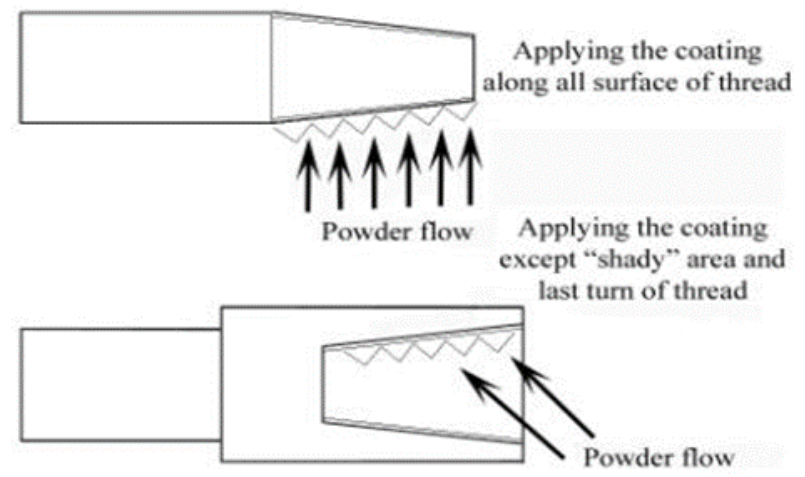

Fig. 4 Application of wear resistant coating schematic [1]

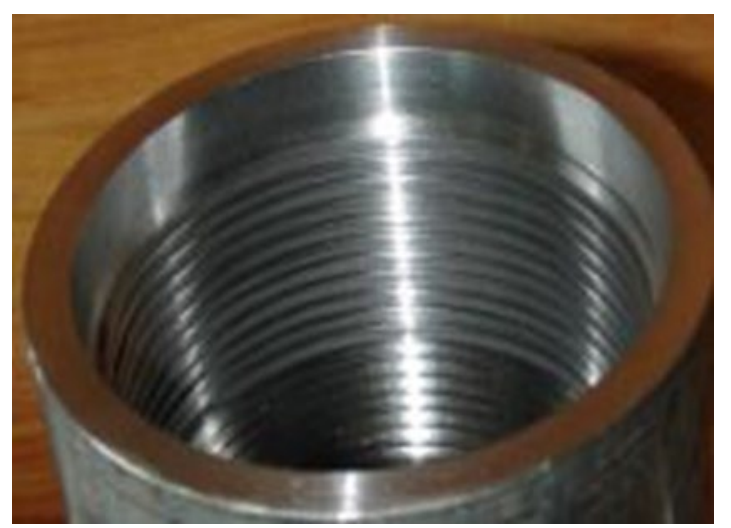

Fig. 5 LAT box thread after AfUFT

The comparative tests on the experimental LAT threaded connections were performed on the "make up/break out" bench, and after that the wear rate of the thread profile was determined by metallographic tools. The overall results proved the conclusions of friction tests: the highest effect of contact surfaces modifications is ensured by nickel sub-layer application technique with further ultrasonic treatment.

The nature of drill pipe body interaction with the casing or borehole wall, differ from tribo-technical conditions in threads. Interaction of the drill pipe with the rock takes place at the higher energy level and may be characterized as impact-abrasive. The coatings in this case shall be thicker (thousands of microns) and demonstrate higher strength, adhesion and cohesion.

The value of energy flow while application of metallized coatings is known to be in relation with the value of formed adhesion bonds of the coating with the substrate: the larger is the flow of energy, the higher is the value of coating adhesion. The (1) detonation and (2) arc spraying methods of metallized coatings application on the aluminum surface were selected as a compromise between the level of formed adhesion bonds in the coating and the level of overheating (softening) of pipe surface.

The coated samples were tested in the conditions simulating both the contact of the pipe with rock (granite) and with the casing. The wear resistance of the best coated aluminum sample surface (coating \#3 $40 \mathrm{X} 13$ applied by arc spraying) in comparison with the witness (without coating) increased by more than 10 times, allowing to forecast wear resistance of the coated aluminum drill pipes on the level of steel drill pipes [1].

\subsection{Contact corrosion}

Inclusion of components made of dissimilar metals into the structure to be operated in the corrosive environment always poses a hazard of contact corrosion. The extent of this hazard is determined basically by the difference of electrochemical potentials (ECP) between contacting metals and $\triangle \mathrm{ECP} \geq 100 \mathrm{mV}$ is already significant for contact corrosion initiation.

The LAIDP made of $1953 \mathrm{~T} 1$ or D16T aluminum alloys uses steel tool joints, and the value of $\triangle \mathrm{ECP}$ is about $350-460 \mathrm{mV}$. Contact corrosion does not usually define the pipe service life, but in some cases, with specific borehole conditions, the corrosion between the joint and the pipe can take a lead in its influence over other negative factors such as wear and fatigue (Fig. 6). There is no direct danger for operations, because this is internal upset pipe area. 


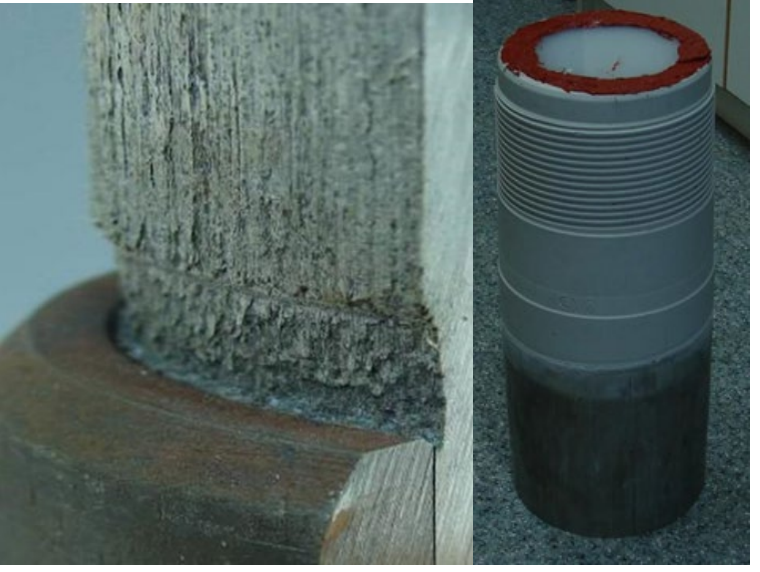

Fig.6. Sample of LAIDP90x9P - 1953T1 affected by contact corrosion after 1300 hours of operations (left photo); LAIDP thread with MAO coating

A very efficient method of protection of the aluminum pipe near-joint area can be the barrier ceramic coating by micro-arc oxidation (MAO) applied to the entire surface of the pipe thread and on $3-5 \mathrm{~cm}$ of the adjacent part most exposed to contact corrosion, see right photo on Fig. 6.

\section{Integrated solution of SAA application problems in drilling riser}

\subsection{Aluminum alloys used in ADR-DW [8]}

The aluminum alloy grade for the main riser pipe was selected based on the following characteristics:

- Sufficient process ductility for manufacturing of heavy wall tubular with the OD of $550-570 \mathrm{~mm}$ and wall thickness of $30-40 \mathrm{~mm}$;

- Acceptable weldability with the welded connection strength close to the base material $(0.80-0.85)$;

- Acceptable corrosion resistance of the base metal and its welded connections in sea water.

The aluminum alloy grades for service pipes were selected without regard to weldability but subject to the increased strength (internal working fluid pressure in the pipe of up to $100 \mathrm{MPa}$ ).

The results are shown in Table 3.

Table 3. Selection of SAA for the main riser components

\begin{tabular}{|l|c|c|c|}
\hline Parameters & $\begin{array}{c}\text { Flange and } \\
\text { main pipe }\end{array}$ & $\begin{array}{c}\text { Service } \\
\text { lines and } \\
\text { couplings }\end{array}$ & Clamps \\
\hline $\begin{array}{l}\text { Alloy } \\
\text { systems }\end{array}$ & $\mathrm{Al}-\mathrm{Zn}-\mathrm{Mg}$ & $\begin{array}{c}\mathrm{Al}-\mathrm{Zn}- \\
\mathrm{Mg}-\mathrm{Cu}\end{array}$ & $\mathrm{Al}-\mathrm{Mg}$ \\
\hline Labeling & $1980 \mathrm{~T} 1$ & $1953 \mathrm{~T} 1$ & $\mathrm{AMG}-5$ \\
\hline $\begin{array}{l}\text { Ultimate } \\
\text { strength, } \\
\text { MPa (ksi) }\end{array}$ & $400(58.01)$ & $530(76.87)$ & \\
\hline $\begin{array}{l}\text { Yield point, } \\
\text { MPa (ksi) }\end{array}$ & $350(50.76)$ & $480(69.62)$ & \\
\hline $\begin{array}{l}\text { Weldability } \\
\text { Good with } \\
\text { heat } \\
\text { treatment of }\end{array}$ & None & Good \\
\hline
\end{tabular}

\begin{tabular}{|l|c|c|c|}
\hline & joint & & Machine \\
$\begin{array}{l}\text { Application } \\
\text { experience }\end{array}$ & $\begin{array}{c}\text { Shipbuilding } \\
\text { industry }\end{array}$ & $\begin{array}{c}\text { Aerospace } \\
\text { industry; } \\
\text { drill pipes }\end{array}$ & $\begin{array}{c}\text { building, } \\
\text { construction } \\
\text { shipbuilding } \\
\text { industry }\end{array}$ \\
\hline
\end{tabular}

The considerable amount of research and development preceded the structure fabrication for the metallurgical production stage of large-size pressed and stamped semis and for the development of welded assembly manufacturing technologies. The results of qualification tests proved material characteristics being acceptable for ADR construction.

For the selected design of the riser section, the welded joint is responsible to a considerable extent for efficiency of the system as a whole. The metal of weld is different from the base metal and is characterized by the presence of individual areas with structural and physical-chemical inhomogeneity. Thus, research and development in the sphere of joint welding procedure were carried out on a priority basis. "Tube-tube" and "flange-tube" welding procedure was developed in the sequence from manual to machine TIG welding and then to MIG welding. Inhomogeneity of welded joint metal is primarily expressed as chemical inhomogeneity and the resulting large range of metal ECP values in the given corrosive environment. The ECP values in the weld area may change in rather significant range - up to $100 \mathrm{mV}$ that is sufficient to initiate corrosion processes even at sufficiently high total corrosion resistance of selected SAA.

\subsection{Active corrosion protection system}

The important metal science issue in ensuring efficiency of the main tubular structures of the risers was the development of its integrated anti-corrosion protection (ACP). The need for such development was defined by the complex polymetallic structure of the riser continuously submerged in the corrosive environment. In this respect, it seems impossible to exclude electrical contacts of dissimilar materials, as well as chemical inhomogeneity of welded joints.

Conventional (passive) corrosion protection such as paints and coatings, electroplating coatings, lubricants, and electrical insulation are not always sufficiently effective. Therefore, the integrated ACP consisting of passive and active (electrochemical) system is preferable. The electrochemical protection system was developed with the use of a mathematical modeling method (see diagram on Fig. 7) allowing for:

- electrochemical protection system optimization;

- corrosion damage diagnostics;

- $\quad$ assessing of corrosion wear in operating conditions. 


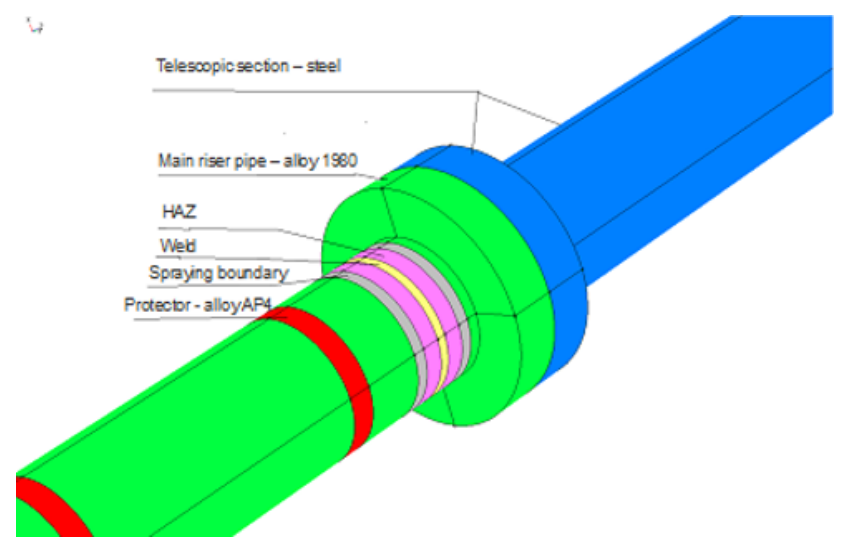

Fig. 7. Diagram of a flange connection on the riser section assumed as the basis for mathematical modeling and anticorrosive protection evaluation

The last passive protection measure, aluminum powder spraying on the places of the highest "chemical contrast", was taken to positively increase ECP values and reduce corrosion flows, respectively.

Such approach to the development of the integrated ACP system allowed to consider virtually all significant design features of the riser, the impact of the corrosive environment, and to reduce the time of designing. This has been proved during the 12 years of riser application offshore Brazil [10].

\section{Conclusion}

Over the past 25 years, in the background of intensively developed well construction technologies there was obtained extensive evidence of the possibility for successful and efficient use of SAA. There are known and successfully tested technical solutions enabling neutralization of SAA properties that limit their application in well construction. Obviously, designing of drilling, casing and production strings, as well as risers and pipelines made of SAA shall not be based on the approaches of adjustment by strength-toweight ratio only, but shall also include the use of the entire wealth of material and semis properties.

\section{Acknowledgments}

The authors dedicate this article to an outstanding specialist in the field of structural aluminum alloys, a brilliant engineer, an excellent manager and friend Valeriy Vasilievich Chizhikov. Valeriy has leading the R\&D works described in this paper and his contribution into the results could not be overestimated - please see Fig. 8.

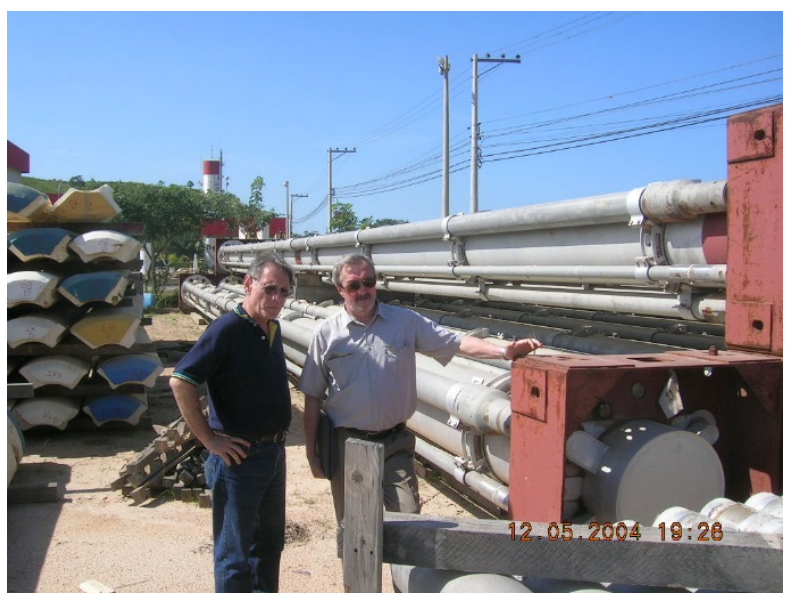

Fig. 8. Alex Adelman (left) and Valeriy Chizhikov with ADRDW riser in Macae, Brasil.

\section{References}

1. M. Gelfgat, V. Chizhikov, S. Kolesov, et al.,"Application of Aluminum Alloy Tube Semis: Problems and Solutions in the Development of Exploration, Production and Transportation Business of Hydrocarbons in the Arctic", paper SPE 166919 (2013)

2. Fain G.M. et al, "Aluminum alloys for offshore drilling systems", Proceedings of the 14-th International Conference on OMAE, Volume I-B, Offshore Technology (1995), pp. 299-306

3. Gelfgat, M.Ya. et al., "Drillstring with aluminium alloy pipes design and practices," paper SPE 79873 (2003)

4. Tikhonov, V.S. et al., "Comprehensive Studies of Aluminium Drillpipe," paper IADC/SPE 128328 (2010)

5. Hong, L.J. et al., "HZ25-4 ERD Challenging Drilling Project-New Strategy and New technology Implementation Are the Keys to Improved Drilling Performance," paper SPE 134949 (2010)

6. Gelfgat, M.Ya. et al., "Aluminium Alloy TubularsAssessment for Ultralong Well Construction," paper SPE 109722 (2007)

7. Gelfgat, M.Ya. et al., "Aluminium Alloys for Casing and Tubing", paper IPTC 14888 (2011)

8. Gelfgat M.Ya. et al., "High-Strength Aluminum Alloys for Deepwater Riser Applications", Proceedings of the Offshore Technology Conference, Paper OTC 16185, Houston, Texas, (2004).

9. Gelfgat M.Ya., Tikhonov, V.S., Chizhikov, V.V., "Aluminum Alloy Risers - Innovation Project Experience for Offshore Oil \& Gas Wells" in the Vestnik Assotsiatsii Burovikh Podryadchikov, v.1, pp.40-47, Moscow, Russia, (2013)

10. Jeffry K. Lehner, Ian Barker, David Walters, "Lightweight Drilling Riser Achieves 12 Years Successful Operation in Offshore Brazil": Paper presented at Offshore Technology Conference, 
Kuala Lumpur, Malaysia, 22-25 March (2016) 9 p.

11. Tikhonov V.S., et al: "Aluminum Catenary Production Riser: Design, Testing Results, Ways to Improvement", Proceedings of the ASME 31st International Conference on Offshore Mechanics and Arctic Engineering, paper OMAE2012-83001, June 10-15, Rio-de-Janeiro, Brazil, (2012)

12. Alikin et al. "Aluminum Riser Assembly", US 2009/0272537A1, United States Patent Application Publication, Nov. 5, (2009) 